\title{
Commentary
}

\section{The Advent of the 4D Mirror World}

\author{
Frédéric Kaplan ${ }^{1, *}$ and Isabella di Lenardo ${ }^{2}$ \\ ${ }^{1}$ Digital Humanities Laboratory, École polytechnique fédérale de Lausanne, 1015 Lausanne, Switzerland; \\ E-Mail: frederic.kaplan@epfl.ch \\ ${ }^{2}$ College of Humanities, École polytechnique fédérale de Lausanne, 1015 Lausanne, Switzerland; \\ E-Mail: isabella.dilenardo@epfl.ch \\ * Corresponding author
}

Submitted: 13 April 2020 | Accepted: 21 April 2020 | Published: 30 June 2020

\begin{abstract}
The 4D Mirror World is considered to be the next planetary-scale information platform. This commentary gives an overview of the history of the converging trends that have progressively shaped this concept. It retraces how large-scale photographic surveys served to build the first 3D models of buildings, cities, and territories, how these models got shaped into physical and virtual globes, and how eventually the temporal dimension was introduced as an additional way for navigating not only through space but also through time. The underlying assumption of the early large-scale photographic campaign was that image archives had deeper depths of latent knowledge still to be mined. The technology that currently permits the advent of the 4D World through new articulations of dense photographic material combining aerial imagery, historic photo archives, huge video libraries, and crowd-sourced photo documentation precisely exploits this latent potential. Through the automatic recognition of "homologous points," the photographic material gets connected in time and space, enabling the geometrical computation of hypothetical reconstructions accounting for a perpetually evolving reality. The 4D world emerges as a series of sparse spatiotemporal zones that are progressively connected, forming a denser fabric of representations. On this 4D skeleton, information of cadastral maps, BIM data, or any other specific layers of a geographical information system can be easily articulated. Most of our future planning activities will use it as a way not only to have smooth access to the past but also to plan collectively shared scenarios for the future.
\end{abstract}

\section{Keywords}

3D models; Mirror World; photo archives; photogrammetry; virtual globes

\section{Issue}

This commentary is part of the issue "Territories in Time: Mapping Palimpsest Horizons" edited by Chiara Cavalieri (UCLouvain, Belgium) and Elena Cogato Lanza (EPFL, Switzerland).

(c) 2020 by the authors; licensee Cogitatio (Lisbon, Portugal). This article is licensed under a Creative Commons Attribution 4.0 International License (CC BY).

The 4D Mirror World can be defined as a global spatiotemporal platform offering diachronic 3D representations of the entire Earth. In its asymptotic form, it features a quasi-continuous representation of the world in motion, virtually embedding all the photographic perspectives, all the data gathered and simulated, both for the foreseen future and the recorded past. This digital twin of the Earth is an object impossible to see in its entirety, a future world-size machine to live "inside." Its territory is potentially so big that many parts will only be "seen" by machines and not by a single human. The platform does not exist yet, but it already has a long history, being in some sense the extension of century-long enterprises to model cities, landscapes, and territories. It is important to replace its most recent technological developments in the long transformation of the photographic medium enabling not only to document and measure the present but also to build a time-indexed metric model of the past and the future on a planetary scale.

The first key innovation took place between 1860 and 1870 , when the photogrammetric method, which combined the technical characteristics of triangulation with the photographic survey, was introduced simultaneously in France and Germany. In 1862, Aimé Laussedat sug- 
gested the French administration adapt the surveying methods using photographic measures instead of the traditional geodesic methods. Laussedat, an engineer from Ecole Polytechnique and an astronomy scholar, realized that measurements based on photographs could serve to geometrically map very significant extensions of spatial territories. He first used stereoscopic views, invented by David Brewster in London, during the measurement process by combining them with the principle of Wollaston's polished chamber. Laussedat called this new method métrophotographie, the iconometry applied to photographic evidence (Laussedat, 1899).

Meanwhile, in Germany, Albrecht Meydenbauer was applying the principles of geodesic triangulation to the study and preservation of monuments, when he discovered Laussedat's photography instruments. In 1867, he made demonstrations on how photography could be used to survey terrain and architectural objects and coined the term "photogrammetry" to describe this new way of measuring using photographic survey (Meydenbauer, 1869). His work contributed to the largest 19th century photographic archive of cultural heritage in the world and his research led to the foundation of the Royal Prussian Photogrammetric Institute, the first photogrammetric institution in the world. Between 1885 and 1909, the institute took about 11,000 survey photographs of around 1200 Prussian monuments.

Laussedat and Meydenbauer's methods implied taking photographs from different positions, which formed intersecting rays. Homologous pairs of points define underlying pivot points and the internal articulation of all the pivot points allows constructing an underlying virtual model. This virtual reality has a precise geometrical structure as each pivot point could relate to the source photographs and one another through simple rotation and translations.

The advent of photography has made possible not only the development of photogrammetry but also an epistemological revolution regarding cartographic representation. The first aerial photograph of the city was taken by Felix Tournachon, alias Nadar, in 1858 from an aerostatic balloon over the Bievre valley in France. However, the real breakthrough in the technology of photographic representation of urban spaces was introduced by Julius Neubronner in 1903, who patented a system for attaching small cameras to pigeons which, connected to a timer, took photos every 30 seconds. The serial photo for the urban landscape and the aerial photographic survey was born. This invention immediately found application in the military field, and the evaluation of natural disasters, as is the case of San Francisco after the terrible earthquake in 1906. The first photo plan of a city was realized in 1911 by Cesare Tardivo, who documented the city of Venice thanks to the aerostatic balloon. To do so, a "mosaic" technique was developed which from then on was the most used method, and still is today, in other urban cases. Aerial photography has moved cartography towards the total coincidence between the map and the world.
In the first decades of the twentieth century, the aim was then to increase the altitude of the photographic more and more and, thus, to map ever-larger portions of the territory. After many expeditions, it was Captain Albert Stevens who managed to raise the point of survey so high that he could capture, in 1930, the first image of the curvature of the earth. With the first satellite images, in 1957, the history of cartographic representation changed profoundly, abandoning the idea of the optical model embraceable by the human gaze, to the symbolic, virtual model of the entire terrestrial globe, understandable in detail only thanks to a sophisticated mathematical model.

The symbolic and practical use of globes to represent planetary-scale maps has a history of its own (Sloterdijk, 1999/2014). During the 19th century, several globes were implemented or projected to be used as giant immersive exhibition setups permitting the embrace of the entire planet: Wylde's Globe in Leicester Square in 1851 or Elisée Reclus' 160-meter wide Globe, an unrealized project for the Universal Exhibition of 1900 (Alavoine-Muller, 2003). Closer to us, Buckminster Fuller's Geoscope in 1962 planned a large spherical 3D display, connected to an array of computers, claimed to be 'the most accurate global representation of our planet ever to be realized' (Buckminster Fuller, 1981). With the Geoscope, Buckminster Fuller developed a series of core ideas for displaying and interacting that would then be implemented in the context of Virtual Globes.

In 1992, the Science Fiction writer Neal Stephenson anticipated the forthcoming arrival of a virtual model of the Earth in his novel Snow Crash describing a piece of software called Earth as 'a globe about the size of a grapefruit, a perfectly detailed rendition of Planet Earth, hanging in space at arm's length in front of his eyes' (Stephenson, 1992). The novel was mentioned as an inspiration for the software EarthViewer that John Hanke, Avi Bar-Zeev, and their team started to develop in 1999 at Keyhole (Crampton, 2008). Just a year before, Al Gore had given a speech picturing the concept of a digital Earth model: 'I believe we need a Digital Earth. A multi-resolution, three-dimensional representation of the planet, into which we can embed vast quantities of geo-referenced data' (Gore, 1998). Thanks to Al Gore's political impulse, previously classified satellite imagery became commercially available, opening a concrete avenue for high-resolution virtual globes.

Keyhole's EarthViewer was not the first virtual globe ever, but certainly one of the best that would run nicely on a normal personal computer, enabling smooth rotation and zooming. In 2005, after Keyhole was bought by Google, the software would ultimately become known as Google Earth. By 2006, Google Earth, as a free-ofcharge service, already had an important cultural impact. Beyond the planetary scale representation, the zooming feature, itself reminiscent of the 1978 film Powers of Ten (Boeke, Eames, \& Eames, 1978), was certainly one of the most impressive features. As an article in Nature summa- 
rized: 'The appeal of Google Earth is the ease with which you can zoom from space right down to street level, with images that in some places are sharp enough to show individual people' (Butler, 2006).

Natural navigation inside a digital twin of the Earth rapidly became a feature that would go beyond the historically anchored globe metaphor. The process of machine-based documentation of street-level images had already been engaged by some artistic works. On July 8, 1973, Ed Ruscha documented Hollywood Boulevard back and forth, loading a continuous strip of 10-meter film into a motor-drive camera, shooting the boulevard in its entire length frame-by-frame (Ruscha, 2005). In 1978, the Aspen Movie Map developed in Nicholas Negroponte's Architecture Machine lab at MIT made the first prototype of interactive navigation inside a "scanned" city. These early experiments paved the way to the first version of the Mirror World Concept. David Gelernter, Professor of Computer Science at Yale University coined the term in 1991, introducing it in the following way:

You will look into a computer screen and see reality. Some part of your world-the town you live in, the company you work for, your school system, the city hospital-will hang there in a sharp colour image, abstract but recognizable, moving subtly in a thousand places. This Mirror World you are looking at is fed by a steady rush of new data pouring in through cables. (Gelernter, 1991)

In 2019, Kevin Kelly stressed the relevance of revamping the Mirror World concept as the proper way of envisioning the advent of a "third platform," a kind of convergence of the now extremely advanced Google Earth Computational Engine and a planetary-scale virtual environment:

The first big technology platform was the web, which digitized information, subjecting knowledge to the power of algorithms; it came to be dominated by Google. The second great platform was social media, running primarily on mobile phones. It digitized people and subjected human behavior and relationships to the power of algorithms, and it is ruled by Facebook and WeChat....We are now at the dawn of the third platform, which will digitize the rest of the world. On this platform, all things and places will be machine-readable, subject to the power of algorithms. (Kelly, 2019)

For Kelly (2019), the Mirror World will not only be a digital twin of the entire planet, but it will also be a temporally adjustable 4D Model (3D + Time):

History will be a verb. With a swipe of your hand, you will be able to go back in time, at any location, and see what came before....or you'll scroll in the other di- rection: forward....These scroll-forward scenarios will have the heft of reality because they will be derived from a full-scale present world. In this way, the Mirror World may be best referred to as a $4 \mathrm{D}$ world.

Buckminster Fuller's Geoscope was already anticipating its virtual globes as a time machine, in the past and a collectively simulated future:

The Geoscope's electronic computers will store all relevant inventories of world data arranged chronologically, in the order and spacing of discovery, as they have occurred throughout all known history....The consequences of various world plans could be computed and projected, using the accumulated historylong inventory of economic, demographic, and sociological data. All the world would be dynamically viewable and picturable and radioable to all the world, so that common consideration in a most educated manner of all world problems, by all world people, would become a practical every day, hour and minute event. (Buckminster Fuller, 1981)

More recently, the development of this $4 \mathrm{D}$ World is the core objective of the Time Machine Project, selected in 2019 by the European Commission as one of the six most important large-scale research initiatives for Europe's future (Abbott, 2019). Central to the project vision is a series of new concepts fed by the recent progress of artificial intelligence and science, articulated around the structuring processes of "Big Data of the Past," a distributed digital information system re-documenting Europe's extremely dense archival recording and its realignment with high-resolution 4D models. Conducting at industrial scales these redocumentation processes and the alignment of multiple fictional spaces resulting from the interpretation of this massive wealth of new data sources are some core challenges of the introduction of the 4th dimension (Kaplan \& di Lenardo, 2017).

In some sense, the 4D World closes the loop of the historical journey that has led from the massive photographic campaign of the 19th century to the Mirror Worlds. The underlying assumption of early large-scale photographic campaigns, responsible for this huge documentary impulse, was that image archives had deeper depths of latent knowledge still to be mined beyond the initial project that leads to their collection (Mitman \& Wilder, 2016). The technology that permits the advent of the $4 \mathrm{D}$ world today through new articulation of dense photographic material combining aerial imagery, historic photo archives, huge video libraries, and crowd-sourced photo documentation precisely exploits this latent potential. In a natural extension of the methodology developed by Laussedat (1899) and Meydenbauer (1869), homologous points can connect not only different photographic perspectives of the same site but also articulate photographic material in time, opening the avenues for hypothetical reconstructions of the past. Thus, as the 
network of homologous pairs extends in time and space, the 4D world emerges as a series of sparse spatiotemporal zones that get progressively connected forming a denser fabric of representations. Information of cadastral maps, BIM data, or any other specific layers of a geographical information system can be easily articulated on this progressively extending 4D skeleton (Kaplan \& di Lenardo, 2020).

Prospects are immense. If indeed 4D Mirror Worlds are the "third platform," most of our future planning activities will use the 4D World as a way not only to have smooth access to the past but also to plan collectively shared scenarios for the future. Giving both decisionmakers and citizens an intuitive interface enabling to go backward in the collectively reconstructed past and forward in the commonly negotiated future is likely to profoundly change our understanding and everyday engagement of the city, the landscapes, and the world.

\section{Conflict of Interests}

The authors declare no conflict of interest.

\section{References}

Abbott, A. (2019). Europe's next €1-billion science projects: Six teams make it to final round. $\mathrm{Na}$ ture, 566(7743), 164-165. https://doi.org/10.1038/ d41586-019-00541-y

Alavoine-Muller, S. (2003). Un globe terrestre pour l'Exposition universelle de 1900. L'utopie géographique d'Élisée Reclus [A globe for the World's Fair of 1900. The geographical utopia of Elisée Reclus]. L'Espace Géographique, 32(2), 156-170.

Boeke, K. (Writer), Eames, C., \& Eames, R. (Directors). (1978). Powers of ten: A film dealing with the relative size of things in the universe and the effect of adding another zero [Motion picture]. Santa Monica, CA: Pyramid Film \& Video.

Buckminster Fuller, R. (1981). Critical path (2nd rev. ed.). New York, NY: Saint Martin's Griffin.
Butler, D. (2006). Virtual globes: The web-wide world. Nature, 439(7078), 776-778. https://doi.org/10.1038/ $439776 a$

Crampton, J. W. (2008). Keyhole, Google Earth, and 3D Worlds: An interview with Avi Bar-Zeev. Cartographica: The International Journal for Geographic Information and Geovisualization, 43(2), 85-93. https:// doi.org/10.3138/carto.43.2.85

Gelernter, D. (1991). Mirror worlds, or: The day software puts the universe in a shoebox.... How it will happen and what it will mean. Oxford: Oxford University Press.

Gore, A. (1998). The digital earth: Understanding our planet in the 21st century. Paper presented at the California Science Center, Los Angeles, USA.

Kaplan, F., \& di Lenardo, I. (2017). Big data of the past. Frontiers in Digital Humanities, 4. https://doi.org/ 10.3389/fdigh.2017.00012

Kaplan, F., \& di Lenardo, I. (2020). Building a mirror world for Venice. In A. Lowe, E. Mitchell, N. Béliard, G. Fornaciari, T. Tomassini, \& G. Damone (Eds), The aura in the age of digital materiality (pp. 197-201). Milan: SilvanaEditoriale.

Kelly, K. (2019, February 12). AR will spark the next big tech platform: Call It mirrorworld. Wired. https:// www.wired.com/story/mirrorworld-ar-next-bigtech-platform

Laussedat, A. (1899). La Métrophotographie [Metrophotography]. Paris: Gauthier-Villars.

Meydenbauer, A. (1869). Die photographische Camera als Messinstrument [The photographic camera as a survey instrument]. Deutsche Bauzeitung, 3(32), 381-383.

Mitman, G., \& Wilder, K. (Eds.). (2016). Documenting the world. Chicago, IL: University of Chicago Press.

Ruscha, E. (2005). Then and now. Göttingen: Steidl.

Sloterdijk, P. (2014). Globes: Spheres. Volume II: Macrospherology. Cambridge, MA: MIT Press. (Original Work published in 1999)

Stephenson, N. (1992). Snow crash. New York, NY: Bantam Books.

\section{About the Authors}

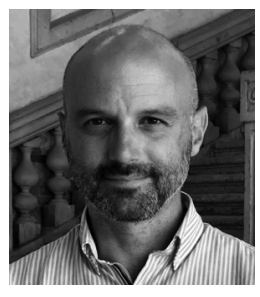

Frédéric Kaplan holds the Digital Humanities Chair at EPFL, where he directs the Digital Humanities Laboratory (DHLAB). He conducts research projects combining artificial intelligence and cultural heritage digitization. He is the coordinator of the Time Machine European Project and president of the Time Machine Organisation, a project that aims at creating a planetary-scale infrastructure giving free and direct access to Big Data of the Past.

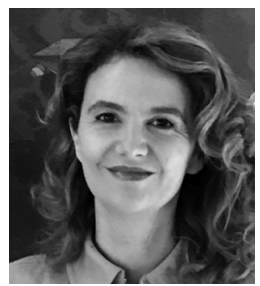

Isabella di Lenardo is a Researcher in Digital Humanities and Urban History at EPFL. She is a specialist in cultural heritage digitization and digital urban reconstruction. She has worked on many projects in collaboration with leading European institutions such as the Bibliothèque nationale de France, the Louvre, the Institut national d'Histoire de l'Art, the Getty Research Foundation and the Giorgio Cini Foundation. 